\title{
Big data analytics in electronic markets
}

\author{
Eric W. T. Ngai ${ }^{1}$ Angappa Gunasekaran ${ }^{2}$ Samuel Fosso Wamba ${ }^{3} \cdot$ \\ Shahriar Akter ${ }^{4} \cdot$ Rameshwar Dubey $^{5}$
}

Received: 26 May 2017 / Accepted: 29 May 2017 /Published online: 9 June 2017

(C) Institute of Applied Informatics at University of Leipzig 2017

\section{The era of big data}

In the past, the main challenge that businesses faced had to do with operating under conditions of data scarcity. Decisionmaking was subject to incomplete, insufficient, and timelapsed data. However, such challenge no longer exists, given the current exponential growth of data available to businesses. Instead, the challenge that businesses now face has to do with the sheer abundance of data. Up until 2003, only 5 exabytes (1018 bytes) of data were available, whereas nowadays the

Eric W. T. Ngai

eric.ngai@polyu.edu.hk

Angappa Gunasekaran

agunasekaran@umassd.edu

Samuel Fosso Wamba

s.fosso-wamba@tbs-education.fr

Shahriar Akter

sakter@uow.edu.au

Rameshwar Dubey

rameshwardubey@gmail.com

1 The Hong Kong Polytechnic University, Hong Kong, China

2 University of Massachusetts Dartmouth, North Dartmouth, MA, USA

3 Toulouse Business School, Toulouse, France

4 University of Wollongong, Wollongong, NSW, Australia

5 Montpellier Business School, Montpellier Research in Management, Montpellier, France same amount of data can be created within two days (Sagiroglu and Sinanc 2013).

\section{Big data in electronic markets}

Businesses now have more data than they can effectively use; as a result, a new critical issue is emerging: big data analytics. The term big data refers to "data sets with sizes beyond the ability of common software tools to capture, curate, manage, and process the data within a specific elapsed time" (Bharadwaj et al. 2013, p. 447). The ability to manage big data, information, and knowledge to gain competitive advantage becomes increasingly important in enabling data-driven decisions in businesses. Indeed, big data has been defined as "a holistic process that involves $5 \mathrm{~V}$ (volume, velocity, variety, value, and veracity) in terms of collection, analysis, use, and interpretation of data for various functional divisions, with a view to gaining actionable insights, creating business value, and establishing competitive advantages" (Fosso Wamba et al. 2015 p. 235).

Electronic markets are particularly inseparable from big data analytics, given that the accomplishments fuelled by big data analytics are primarily generated from the electronic market community, as in the case of the product recommender systems introduced by electronic market leaders, such as eBay and Amazon (Chen et al. 2012). The data of the electronic market are more visible and easier to collect than those of traditional markets because the former can be collected through screenscraping and agent-based data collection approaches (Chang et al. 2014). Big data analytics has opened opportunities to practitioners of the electronic market to listen to the voice of the market, including customers, employees, investors, and media, through different sources, such as newsgroups and social media 
sites. For academics, these opportunities represent another broad and encompassing area of research.

To successfully implement big data analytics, businesses must overcome not only technological obstacles, such as data acquisition and management, but also managerial obstacles, such as understanding how to use analytics to improve business performance. Given the importance of the above challenges and issues, big data analytics has increasingly attracted the attention of scholars. In a similar spirit, Akter and Fosso Wamba (2016, p.190) state "Big data analytics (BDA) increasingly provides value to e-commerce firms by using the dynamics of people, processes, and technologies to transform data into insights for robust decision making and solutions to business problems".

\section{Focus of the special issue}

The core objective of this special issue is to provide a platform through which academics and practitioners can exchange views, share skills and knowledge, and understand how big data analytics can significantly help businesses in the electronic markets to create added value.

The call for papers generated a number of submissions but not all of them met the criteria of this special issue. After three or four rounds of reviews process, three papers were finally accepted. The papers appearing in this special issue explore the way how data analytics create values for businesses through various perspectives, including analyzing big data from mobile phone Apps and social media networks, and extract investor sentiment through text-mining big data.

The first paper, titled "Electronic Mobility Market Platforms - A Review of the Current State and Applications of Business Analytics", by Christoph Willing, Tobias Brandt, and Dirk Neumann, focus the application of mobility services on transportation mode. Thanks to the technological advancements and digitization, multimodal mobility platforms (MMPs) emerged to provide customers different transport options and help them find the best route the best route. These electronic transactions generate vast amounts of data, providing platform operators and mobility providers with new business analytics opportunities. The authors firstly evaluate the business model of mobility platforms using the VISOR model to observe the current state of active MMP. Although several platforms offer multimodal trip comparison and booking services, there still seems to be no single established standard.

To explore how stakeholders can benefit from analyzing the data gathered on MMPs, the authors then present three case studies that outline the role of analytics in improving and optimizing urban mobility business models. Through analyzing big data, the authors suggest possibilities to transform the business model of MMPs more profoundly by presenting new revenue generation opportunities such as a data brokerage approach.
The second paper authored by Ricardo Buettner has the title "Predicting user behavior in electronic markets based on personality-mining in large online social network: A personality-based product recommender framework". To predict a user's personality and to subsequently derive its personality-based product preferences, the author propose a personality-based product recommender (PBPR) framework to analyze social media data. The PBPR framework is evaluated as an IT-artefact with a unique online social network XING (an important career-oriented online social network site in Europe) dataset and a unique coffeemaker preference dataset. Since this framework is built on a fundamental theoretical basis, the author contributes to theory-based IT-artefacts incorporating big data and social media analytics in electronic markets and can significantly help businesses in the electronic markets to create added value.

The proposed framework is able to predict all of the big five traits at an ideal accuracy levels and not just one trait or extreme personality cases. With the unique XING dataset, a predictive gain between 23.2 and $41.8 \%$ by applying a generalized linear model for personality trait prediction was reached. And, the possibility of recommending products based on a user's personality can reach a predictive gain of $45.1 \%$. The results in this paper show that it is possible to predict a user's personality comprehensively from online social network data and that businesses in electronic markets can create added value by improving product recommendations.

In the third paper, titled "Market sentiment dispersion and its effects on stock return and volatility", Eric. W.K. See-To and Yang Yang consider how to directly measure investor sentiment and quantify stock market valuation. Before the era of big data, research uses proxies as a mediator to indirectly measure investor sentiment, which has proved elusive due to insufficient data points. This research is one of the earliest attempts to measure the sentiment and its dispersion for individual investors.

Leveraging on development of big data and recent advances in data and text mining techniques, the authors used a text mining method to extract sentiment from 1,170,414 data points captured from Twitter and applied both linear regression and Support Vector Regression to show that sentiment dispersion contains information about the stock volatility and stock returns. This study not only highlights the role played by sentiment dispersion of investors on the stock market but also carries significant managerial implications for the use of social media as a strategic tool to conduct stock price evaluation and prediction.

\section{Thank you editorial team and reviewers}

Finally, the Guest Editors would like to express our sincere gratitude to the Senior Editor, Prof. Harry Bouwman and the Executive Editor Carsta Militzer-Horstmann for their encouragement and support throughout this special issue project. 
Also, our sincere thanks go to our reviewers who have read the manuscripts for this special issue. Without their timely reviews, this special issue would not have been possible. Last but not least, we are grateful to all the authors who have submitted papers to this special issue.

\section{References}

Akter, S., \& Fosso Wamba, S. F. (2016). Big data analytics in E-commerce: A systematic review and agenda for future research. Electronic Markets, 26(2), 173-194.
Bharadwaj, A., El Sawy, O., Pavlou, P. A., \& Venkatraman, N. (2013). Digital business strategy: Toward a next generation of insights. MIS Quarterly, 37(2), 471-482.

Chang, R. M., Kauffman, R. J., \& Kwon, Y. (2014). Understanding the paradigm shift to computational social science in the presence of big data. Decision Support Systems, 63, 67-80.

Chen, H., Chiang, R. H. L., \& Storey, V. C. (2012). Business intelligence and analytics: From big data to big impact. MIS Quarterly, 36(4), $1165-1188$.

Fosso Wamba, S., Akter, S., Edwards, A., Chopin, G., \& Gnanzou, D. (2015). How 'big data' can make big impact: Findings from a systematic review and a longitudinal case study. International Journal of Production Economics, 165, 234-246.

Sagiroglu, S., \& Sinanc, D. (2013). Big data: A review. In: Proceedings of the 2013 international conference on collaboration technologies and systems (CTS), pp 42-47. 